\title{
Ophthalmological findings in Cameroonian boxers
}

This article was published in the following Dove Press journal:

Clinical Ophthalmology

12 June 2017

Number of times this article has been viewed

\section{Giles Kagmeni ${ }^{1,2}$ \\ Georges Nguefack-Tsague ${ }^{3}$ \\ Steve Robert Ebana Mvogo ${ }^{2}$ \\ Come Ebana Mrogo ${ }^{2,4}$}

'Eye Department, University Teaching Hospital Yaoundé (UTHY), ${ }^{2}$ Eye

Department, University of Yaoundé I,

${ }^{3}$ Public Health Department, University

of Yaoundé I, ${ }^{4}$ Eye Department,

Central Hospital Yaoundé, Cameroon
Background: The purpose of this prospective, noncomparative consecutive study was to examine active and retired amateur boxers in order to evaluate the nature and incidence of ocular pathologic conditions related to the boxing practice.

Results: A total of 35 boxers were included in this study. The mean age of the boxers was $28.09 \pm 7.57$ years (range 18-52 years). Sixteen (45.7\%) boxers had $>5$ years of boxing experience. Fifteen (42.85\%) of the boxers reported wearing protective equipment in the bouts and sparring rounds. The number of bouts ranged from 3 to 103, with a median of 20 (interquartile range $[\mathrm{IQR}]=7-44)$. The percentages of wins varied from $25 \%$ to $100 \%$, with a median of $68.29 \%$ (IQR $=50.00-79.54)$. Most of the eye injuries recorded were minor injuries $(66.66 \%)$, with subconjunctival hemorrhage being the most common (24.24\%). Lid scars were the second most common lesion, accounting for $18.18 \%$ of all lesions. Sight-threatening eye lesions accounted for $33.34 \%$ of injuries and included cataracts $(12.12 \%)$, lens dislocation $(3.03 \%)$, pseudoexfoliation syndrome (3.03\%), unilateral glaucoma (3.03\%), retinal detachment $(3.03 \%)$, vitreous opacity (6.06\%), and lattice degeneration (3.03\%).

Conclusion: Boxing-related ocular traumas are common in Cameroon, and ocular surface lesions are the most common injury reported. Severe lesions are indications for premature retirement from boxing practice.

Keywords: boxer, subconjunctival hemorrhage, traumatic cataract

\section{Introduction}

Boxing is a popular combat sport in which opponents administer punches to the anterolateral part of the face, the chest and the abdomen, above the belt line. The eyes and nose are, therefore, the most exposed body parts. Eye trauma in boxing depends on many factors, including the distance of the blow, the power and placement of the fist, and the use of protective equipment. ${ }^{1}$ Complications related to the practice of this sport are well-documented. ${ }^{2,3}$ Signs of eye injuries are found in $41 \%$ to $76 \%$ of boxers. ${ }^{4,5}$ These injuries can affect all structures of the eye and can result in permanent loss of sight. Classically, three mechanisms have been described to explain eye damage in boxing: direct (coup), indirect (countercoup), and equatorial expansion. ${ }^{6}$ However, a fourth mechanism namely "suction effect" has been described by Vinger and Capão Filipe. ${ }^{7}$ Some of these lesions can be ignored, whereas others must be sought for early treatment. ${ }^{4}$ To the best of our knowledge, no study has previously documented boxing-related eye complications in Sub-Saharan Africa.

The purpose of our study was to highlight the prevalence, nature, and risks of eye injuries in boxers practicing in Cameroon.

\section{Patients and methods}

This prospective and descriptive study was conducted in the ophthalmology service of the Yaoundé Teaching Hospital (YTH) from June 1 to December 31, 2012. All 
boxers affiliated with the Cameroon Boxing Federation, whether they were amateurs or professionals, active, or retired, were included in the study. The study was approved by the Research Ethics Board of YTH. Written informed consent was obtained from participants for this study. Written informed consent to publish picture was also obtained from the patient (Figure 1).

The research was in compliance with the Helsinki Declaration. Socioprofessional parameters such as age, gender, boxing experience (number of years of boxing practice), number of fights, the performance of the boxers, and the frequency of training were obtained from the boxer book.

All included boxers underwent a complete ophthalmologic examination, including best-corrected visual acuity (BCVA), intraocular pressure (IOP) taken by aplanation, slit lamp examination of the anterior segment, and examination of the central and peripheral retina after dilation using the Goldmann three-mirror lens. An automatic visual field (a standard, white/white perimetry on a G1 program with dynamics strategy) examination was carried out in cases of glaucoma suspicion (IOP $>21 \mathrm{mmHg}$ and or optic disc/ cup $>4 / 10$ ). Also, ocular echography mode B was carried out in cases of opacity of the mediums preventing the visualization of the posterior segment.

\section{Statistical analysis}

Data were recorded in Microsoft Excel 2010 and exported to IBM-SPSS version 21 (IBM Corp., Armonk, NY, USA) for statistical analysis. Qualitative variables were reported as number (\%). Continuous variables deviating significantly from normality were reported as median with interquartile range (IQR) and otherwise reported as mean \pm standard deviation. Associations were quantified with odds ratios (ORs)

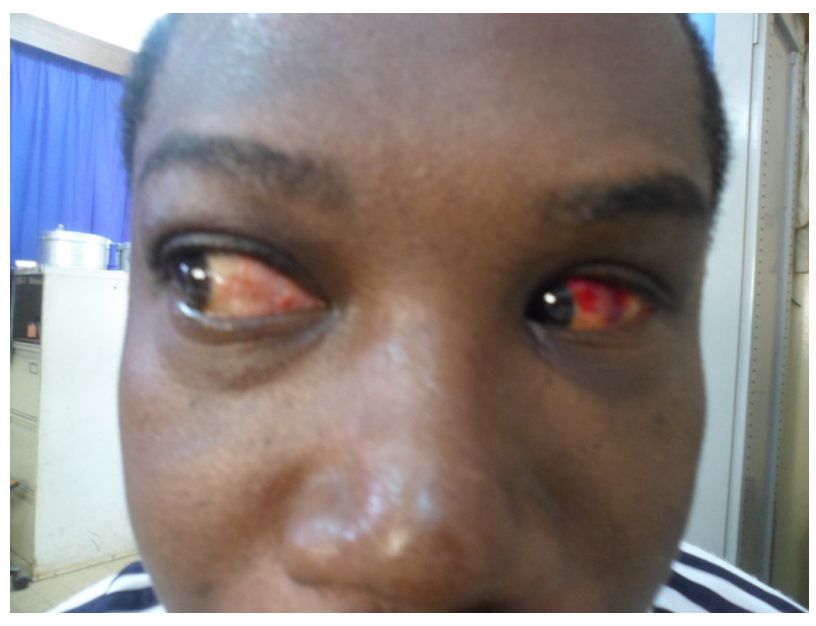

Figure I Subconjunctival hemorrhage. with 95\% confidence intervals (CIs) from logistic regression models. Cochran-Armitage test of trend was used to assess the trend with ordinal variables. Correlations between nonnormally distributed continuous variables were measured by Spearman's rho correlation coefficients. $P$-values $<0.05$ were considered statistically significant.

\section{Results}

Of the 48 boxers contacted, 35 (34 amateurs and 1 professional) participated in the ophthalmologic examination and were retained for this study, resulting in a participation rate of $72.91 \%$. Table 1 summarizes the sociodemographic and professional characteristics of our boxers. There were $30(85.71 \%)$ active boxers and 5 (14.29\%) retired boxers; there was $1(2.9 \%)$ female boxer. Fifteen (42.85\%) of boxers reported wearing protective equipment in the bouts and sparring rounds.

Table I Sociodemographic and boxing career of 35 boxers

\begin{tabular}{ll}
\hline Characteristics & $\mathbf{N}(\%)$ \\
\hline Gender & \\
Male & $34(97.1)$ \\
Female & $1(2.9)$ \\
Age (years) & \\
$\leq 30$ & $26(74.3)$ \\
$>30$ & $9(25.7)$ \\
Boxing experience (years) & \\
$\leq 5$ & $19(54.3)$ \\
$>5$ & $16(45.7)$ \\
Percentage of wins & \\
$\leq 50$ & $8(25.7)$ \\
$5 \mathrm{I}-75$ & $16(45.7)$ \\
$>75$ & $10(28.6)$ \\
Category & \\
Light flyweight & $2(5.7)$ \\
Flyweight & $\mathrm{I}(2.9)$ \\
Bantamweight & $3(8.6)$ \\
Lightweight & $5(14.3)$ \\
Light welterweight & $4(11.4)$ \\
Welterweight & $5(14.3)$ \\
Light middleweight & $6(17.1)$ \\
Light heavyweight & $4(11.4)$ \\
Heavyweight & $3(8.6)$ \\
Super heavyweight & $2(5.7)$ \\
Number of lesions & \\
0 & $17(48.6)$ \\
I & $8(22.9)$ \\
2 & $5(14.3)$ \\
3 & $5(14.3)$ \\
Eye involved & \\
L & $8(22.9)$ \\
R & $7(20.0)$ \\
R/L & $3(8.6)$ \\
None & $17(48.6)$ \\
\hline Abbreviations L, &
\end{tabular}

Abbreviations: L, left; $R$, right. 
The mean age of the boxers was $28.09 \pm 7.57$ years (range: $18-52$ years), with $26(74.3 \%)$ boxers younger than 30 years of age. Active boxers had a mean age of 26.0 (4.2 years [range 18-37]).

Sixteen (45.7\%) boxers had $>5$ years of boxing experience. Competitive weight varied from 46 to $102 \mathrm{~kg}$, with an average of $67.89 \pm 13 \mathrm{~kg}$. The number of bouts ranged from 3 to 103 , with a median of 20 (IQR =7-44). The number of wins was between 1 and 99 , with a median of 15 (IQR $=5-30$ ). The percentages of wins varied from $25 \%$ to $100 \%$, with a median of 68.29 (IQR $=50.00-79.54$ ).

The BCVA was $>6 / 18$ in 64 eyes. Of 6 (eyes), the BCVA was $<6 / 60$. IOP was below $20 \mathrm{mmHg}$ in 69 eyes (98.57\%). One boxer presented an IOP of $28 \mathrm{mmHg}$ in one eye. One or more pathologic findings were observed in 18 $(51.40 \%)$ boxers.

Table 2 summarizes the pathological eye findings. Most of the eye injuries recorded were minor injuries (66.66\%), with subconjunctival hemorrhage being the most common (24.24\%) (Figure 1). Lid scars were the second most common lesion, accounting for $18.18 \%$ of all lesions, followed by posterior synechia (12.12\%) (Figure 2), pupil deformation $(6.06 \%)$, and angle abnormality (6.06\%).

Sight-threatening eye lesions accounted for $33.34 \%$ of eye injuries and included cataracts (12.12\%) (Figure 2), lens dislocation (3.03\%), pseudoexfoliation syndrome (3.03\%), unilateral glaucoma (3.03\%), retinal detachment (3.03\%), vitreous opacity (6.06\%), and lattice degeneration (3.03\%). One boxer presented myopia of -3 diopters.

Seventeen $(48.60 \%)$ of the boxers had no lesions, $8(22.9 \%)$ had 1 lesion, 5 (14.3\%) had 2 lesions, and $5(14.3 \%)$ had 3 lesions. The number of lesions increased with age

Table 2 Ocular findings in 35 boxers

\begin{tabular}{ll}
\hline Characteristics & Total (\%) \\
\hline Minor lesions (22) & \\
Lid scars & $6(18.18)$ \\
Subconjunctival hemorrhage & $8(24.24)$ \\
Posterior synechia & $4(12.12)$ \\
Angle abnormality & $2(6.06)$ \\
Pupil deformation & $2(6.06)$ \\
Sight threatening lesions (II) & \\
Cataract & $4(12.12)$ \\
Lens luxation & I $(3.03)$ \\
Glaucoma & I $(3.03)$ \\
Retinal detachment & I $(3.03)$ \\
Vitreous opacity & $2(6.06)$ \\
Lattice degeneration & I $(3.03)$ \\
Pseudo exfoliation syndrome & I $(3.03)$ \\
Total & $33(100)$ \\
\hline
\end{tabular}

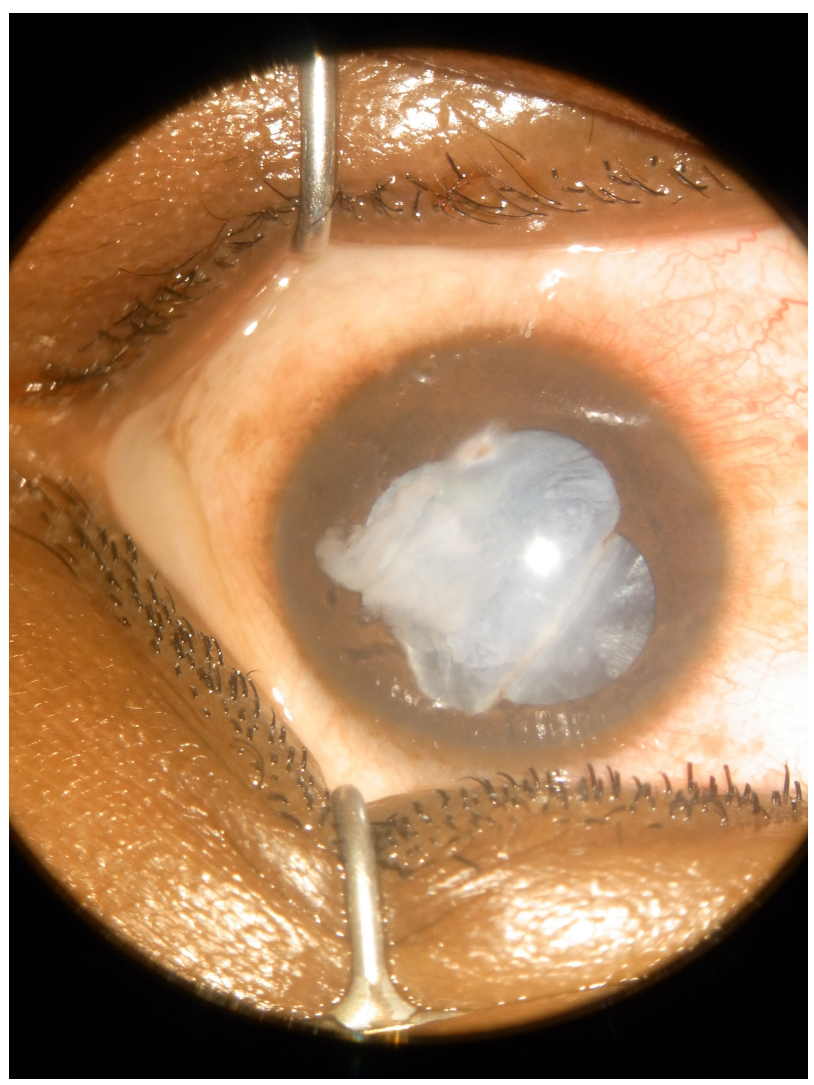

Figure 2 Traumatic cataract.

(Spearman's rho correlation $=0.75 ; P=0.000$ ), boxing experience (Spearman's rho correlation $=0.76 ; P=0.000$ ). The Spearman's rho correlation between the number of bouts and the number of lesions was 0.75 ( $P=0.0001)$; thus, the number of lesions increased significantly with the number of bouts. Table 3 shows the association between age, boxing experience, percentage of wins and boxing category and ocular lesions. In particular, the estimated odds of having lesions was multiplied by 1.16 (OR $=1.16$; 95\% CI: $1.04-1.29)$ for each additional bout ( $16 \%$ increase), 1.60 (OR $=1.60$ [95\% CI: 1.16-2.18], $P=0.04)$ for each additional year $(60 \%$ increase), and 1.73 (OR $=1.73$ [95\% CI: 1.16-2.58], $P=0.008)$ for each additional category ( $73 \%$ increase).

The proportions of boxers with lesions were $88.9 \%$ for those older than 30 years and $38.5 \%$ for younger boxers. The older boxers ( $>30$ years) were nearly 13 times more likely to have lesions than younger boxers ( $\mathrm{OR}=12.8[95 \%$ CI: $1.4-118.32, P=0.025])$. Boxers with $<5$ years of experiences had $21.1 \%$ fewer lesions than boxers with $>5$ years of experience (87.5\%). In fact, more experienced boxers were 26 times more likely to have lesions than less experienced boxers.

The proportion of lesions was higher for boxers with a percentage of wins between $51 \%$ and $75 \%$. Boxers 
Table 3 Association between age, boxing experience, percentage of wins and boxing category and ocular lesions

\begin{tabular}{|c|c|c|c|c|c|}
\hline Category & $\begin{array}{l}\text { None, } \\
\text { n (\%) }\end{array}$ & $\begin{array}{l}\text { At least one } \\
\text { lesion, } n(\%)\end{array}$ & $\begin{array}{l}\text { Total, } \\
\text { n (\%) }\end{array}$ & OR (95\% CI) & $P$-value \\
\hline \multicolumn{6}{|l|}{ Age (years) } \\
\hline$\leq 30$ & $16(6 \mid .5)$ & $10(38.5)$ & $26(74.3)$ & 1 & \\
\hline$>30$ & I (II.I) & $8(88.9)$ & $9(25.7)$ & $\mid 2.8(|.4-| \mid 8.32)$ & 0.025 \\
\hline \multicolumn{6}{|c|}{ Boxing experience (years) } \\
\hline$\leq 5$ & $15(78.9)$ & $4(2 I .1)$ & $19(54.3)$ & 1 & \\
\hline$>5$ & $2(12.5)$ & $14(87.5)$ & $16(45.7)$ & $26.25(4.14-166.45)$ & 0.001 \\
\hline \multicolumn{6}{|c|}{ Percentage of wins } \\
\hline$\leq 50$ & 7 (77.8) & $2(22.2)$ & $9(25.7)$ & 1 & \\
\hline $5 \mathrm{I}-75$ & $6(37.5)$ & $10(62.5)$ & $16(45.7)$ & $5.83(0.90-37.82)$ & 0.06 \\
\hline$>75$ & $4(40.0)$ & $6(60.0)$ & $10(28.6)$ & $5.25(0.70-39.48)$ & 0.10 \\
\hline \multicolumn{6}{|l|}{ Category } \\
\hline $1-3$ & $5(83.3)$ & I (I6.7) & $6(17.1)$ & 1 & \\
\hline $4-7$ & $10(50.0)$ & $10(50.0)$ & $20(57.1)$ & $5.0(0.49-50.83)$ & 0.17 \\
\hline $8-10$ & $2(22.2)$ & $7(77.8)$ & $9(25.7)$ & $17.5(1.22-250.36)$ & 0.03 \\
\hline
\end{tabular}

Notes: The number of lesions increased with age $(P=0.025)$, boxing experience $(P=0.001)$, percentage of wins $(P=0.10)$, and categories $(P=0.008)$. Category $I-10$ are defined as: light flyweight $=1$; flyweight $=2$; bantamweight $=3$; lightweight $=4$; light welterweight $=5$; welterweight $=6$; light middleweight $=7$; light heavyweight $=8$; heavyweight $=9$; super heavyweight $=10$.

Abbreviations: $\mathrm{Cl}$, confidence interval; $\mathrm{OR}$, odds ratio.

with $>75 \%$ of wins and those between $51 \%$ and $75 \%$ were, respectively, 5 (OR $=5.25$ [95\% CI: $0.70-39.48], P=0.1)$ and 6 times $(\mathrm{OR}=5.83$ [95\% CI: $0.90-37.82], P=0.06)$ more likely to have lesions than those with $<50 \%$ of wins.

The proportions of boxers with lesions increased significantly linear with the competitive weight of boxers $(P=0.02)$, with the highest percentage being $77.8 \%$ for those between the light heavyweight and super heavyweight, and the lowest percentage being $16.7 \%$ for those between the light flyweight and bantamweight. Boxers between the light heavyweight and super heavyweight and those between the lightweight and light middleweight were, respectively, 17 (OR =17.5 [95\% CI: $1.22-250.36], P=0.03$ ) and 5 times (OR $=5.0[95 \%$ CI: 0.49-50.83], $P=0.17)$ more likely to have lesions than those in the light flyweight and bantamweight.

\section{Discussion}

The purpose of this prospective study was to determine the prevalence of ocular damages in boxers in Cameroon. The participation rate for the study was $72.91 \%$. The fear of discovering lesions likely to cause disqualification from boxing and lack of motivation are probable reasons for the low participation rate in this study.

The mean age of our boxers (28.4 years) was higher than the 23.1 years reported by Bianco et al. ${ }^{8}$ A possible explanation for this difference is the fact that we included retired boxers. In developed countries, boxers often begin their careers at a younger age. The sex ratio reported in the current study can be attributed to sociocultural beliefs.

The average duration of boxing practice in our athletes is short compared to that reported by Hazar et al in Turkey. ${ }^{9}$
In developed countries, boxers are well-paid, and their medical follow-up is assured. Therefore, they have a long competitive career.

Among the boxers in our study, $85.71 \%$ presented a BCVA of 6/6. Our percentage is lower than those of Hazar and Bianco, whose reported rates are $100 \%$ and $98 \%$, respectively. This is linked to the nature of observed lesions in our series. It is difficult to estimate the real morbidity of ocular injuries suffered by boxers because some complications can arise when the athlete is retired. Five boxers who presented a monocular blindness should have been disqualified from boxing. Mechanisms to explain ocular damage due to blunt trauma have been well-described in previous studies. ${ }^{6,10}$

Eye injuries were found in $18(51.42 \%)$ boxers in our series. Our data are lower than those of Giovinazzo et $\mathrm{al}^{5}$ and Wedrich et $\mathrm{al},{ }^{4}$ whose reported rates are $66 \%$ and $76 \%$, respectively. Only amateur boxers are allowed to participate in the Olympic Games. Unlike professional boxers, amateurs must wear a protective helmet and a light sleeveless shirt.

In our context, eye injuries could be mainly attributed to the irregular use of protective measures. Although headgear does not provide complete protection of the eyes, nose, maxilla, and eyebrows, its use should be mandatory during the bouts and sparring rounds in amateur boxing. ${ }^{11,12}$ In this study, nonheadgear users said that they were not able to buy it. However, they would like to wear it if it prevented injury. Discomfort caused by headgear was the main reason for lack of use reported by Finch et al. ${ }^{13}$

A significant association found between the high prevalence of ocular injuries and high percentages of wins in our study contrasts with the findings from other reports in which 
boxers with a high percentage of bout loss were more likely to sustain ocular injuries. ${ }^{14}$ However, the correlation between ocular injuries and others factors, such as boxing experience and boxing categories, is in agreement with other studies from developed countries.

The high prevalence of subconjunctival hemorrhage may be due to the fact that the study period coincided with a period of intense training related to the preparation for a national boxing championship. In a study involving 956 boxers, Bianco et al also found that subconjunctival hemorrhage and corneal ulcers were the most common eye lesions in boxing. ${ }^{8}$ Posterior synechia is the result of chronic anterior chamber irritation and is the cause of 2 cases of pupil deformation observed in our series. Cataracts were the leading sight-threatening complications $(12.12 \%)$ in our study. According to patient age and the unilaterality of this lesion, it was easy to correlate it with boxing. In a series of 74 boxers Giovinazzo et $\mathrm{al}^{5}$ encountered cataracts in $19 \%$ of cases. The pathophysiology of postconcussive cataracts is not yet well-understood. Capsular rupture of $>2 \mathrm{~mm}$ or disruptions of hydroelectric exchanges at the level of the lens have been incriminated. ${ }^{15}$ The mean age of boxers with a cataract (34.8 years) was significantly higher $(P=0.004)$ than that of those without cataract (26.5 years). However, the mean age of boxers with cataracts is lower than that of patients with cataracts in the general population, which varies from 58 to 62 years, according to surveys carried out in Africa. ${ }^{16,17}$ This suggests that cataracts may appear earlier in boxers. Pseudoexfoliation syndrome was found in 1 boxer, who presented with a total lens luxation in the contralateral eye. Lens dislocation is, generally, caused by a violent eye trauma or minimal trauma in individuals with preexisting zonula fragility. In the large series of 956 boxers, Bianco et al ${ }^{8}$ found that a complete or partial dislocation of the lens was present in $3.6 \%$ of athletes. The rate of retinal detachment $(3.03 \%)$ observed in our boxers was close to that reported by Giovinazzo (3\%). An equatorial expansion mechanism has been proposed to explain peripheral retinal damage due to blunt traumas. ${ }^{18}$ Our study revealed 2 cases $(6.06 \%)$ of angle abnormality. This lesion was associated with unilateral glaucoma in a retired boxer. This is quite low compared with the findings of Giovinazzo et al and Wedrich et al, who, respectively, observed angle abnormalities in $19 \%$ and $16 \%$ of their series. Previously, Ellong et al ${ }^{19}$ found that the prevalence of posttraumatic glaucoma related to irido corneal angle injuries in the Cameroonian population was $2.1 \%$. No cases of glaucoma were found in a series of 20 active amateur boxers in Turkey. ${ }^{9}$
The proportion of boxers with lesions has increased significantly due to many factors. Eye lesions have a deleterious effect on the career of a boxer. In our series, 2 boxers who, respectively, presented a retinal detachment and a total dislocation of the lens prematurely stopped practicing the sport. The strength of this prospective study is the increased awareness of boxing-related eye complications. The limitation of the study are the small sample size (we included 5 retired boxers, just one female and just one professional athlete) and incomplete filling out of the questionnaire concerning the boxing career.

\section{Conclusion}

Boxing-related ocular traumas are common in Cameroon. Subconjunctival hemorrhage and superficial lid scars are the most commonly reported injuries. Sight-threatening lesions are indications for premature retirement from boxing practice. We recommend the effective application of preventive measures, including a complete ophthalmological examination at the beginning of the boxing career and subsequent screening eye examinations both during their active career and their retirement period, as well as the mandatory use of suitable protective equipment.

\section{Author contributions}

GK, GN-T, and SREM contributed to the study design, analyzed the data, and performed critical revision of the manuscript for important intellectual content. GK, GN-T, and CEM wrote the paper. All authors contributed toward data analysis, drafting and revising the paper, read and approved the final manuscript, and agree to be accountable for all aspects of the work.

\section{Disclosure}

The authors report no conflicts of interest in this work.

\section{References}

1. Smith DJ. Ocular injuries in boxing. In: Vinger PF, editor. Prevention of Ocular Sports Injuries. Boston, MA: Little, Brown and Co. 1988: 242-245.

2. Martland HS. Punch drunk. J Am Med Assoc. 1928;91(15):1103.

3. Jordan BD. Chronic traumatic brain injury associated with boxing. Semin Neurol. 2000;20(2):179-185.

4. Wedrich A, Velikay M, Binder S, Radax U, Stolba U, Datlinger P. Ocular findings in asymptomatic amateur boxers. Retina. 1993;13(2): 114-119.

5. Giovinazzo VJ, Yannuzzi LA, Sorenson JA, Delrowe DJ, Cambell EA. The ocular complications of boxing. Ophthalmology. 1987;94(6): 587-596.

6. Wolter JR. Coup-contrecoup mechanism of ocular injuries. Am J Ophthalmol. 1963;56:785-796.

7. Vinger PF, Capão Filipe JA. The mechanism and prevention of soccer eye injuries. Br J Ophthalmol. 2004;88(2):167-168. 
8. Bianco M, Vaiano AS, Colella F, et al. Ocular complications of boxing. Br J Sports Med. 2005;39(2):70-74; discussion 70-74.

9. Hazar M, Beyleroglu M, Subasi M, Or M. Ophthalmological findings in elite amateur Turkish boxers. Br J Sports Med. 2002;36(6):428-430.

10. Benson WE, Shakin J, Sarin LK. Blunt trauma. In: Duane TD, editor. Clinical Ophthalmology. Philadelphia: Harper \& Row Publishers, Inc; 1985;3:1-13.

11. Dickinson P, Rempel P. Prohibiting headgear for safety in amateur Boxing? Opinion of the Canadian Boxing Community: an Online Poll. Sports Med Open. 2016;2:19.

12. Bianco M, Loosemore M, Daniele G, Palmieri V, Faina M, Zeppilli P. Amateur boxing in the last 59 years. Impact of rules changes on the type of verdicts recorded and implications on boxers' health. Br J Sports Med. 2013;47(7):452-457.

13. Finch CF, McIntosh AS, McCrory P, Zazryn T. A pilot study of the attitudes of Australian Rules footballers towards protective headgear. J Sci Med Sport. 2003;6(4):505-511.
14. Bledsoe GH, Li G, Levy F. Injury risk in professional boxing. South Med J. 2005;98(10):994-998.

15. Saleh M. Contusions oculaires à globe fermé. [Closed ocular contusions]. J Fr Ophtalmol. 2012;35(6):445-453. French.

16. Ezegwui IR, Ajewole J. Monitoring cataract surgical outcome in a Nigerian mission hospital. Int Ophthalmol. 2009;29(1):7-9.

17. Isawumi MA, Soetan E, Adeoye A, Adeoti CO. Evaluation of cataract surgery outcome in Western Nigeria. Ghana Med J. 2009;43(4): 169-174.

18. Weidenthal DT, Schepens CL. Peripheral fundus changes associated with ocular contusion. Am J Ophthalmol. 1966;62(3):465-477.

19. Ellong A, Ebana Mvogo C, Nyouma Moune E, Bella-Hiag A, Ngosso A, Njoh Litumbe C. [Post-traumatic glaucoma with irido-corneal angle injuries in Cameroon]. Bull Soc Belge Ophtalmol. 2005;(298):21-28. French.
Clinical Ophthalmology

\section{Publish your work in this journal}

Clinical Ophthalmology is an international, peer-reviewed journal covering all subspecialties within ophthalmology. Key topics include: Optometry; Visual science; Pharmacology and drug therapy in eye diseases; Basic Sciences; Primary and Secondary eye care; Patient Safety and Quality of Care Improvements. This journal is indexed on

\footnotetext{
Submit your manuscript here: http://www.dovepress.com/clinical-ophthalmology-journal
}

\section{Dovepress}

PubMed Central and CAS, and is the official journal of The Society of Clinical Ophthalmology (SCO). The manuscript management system is completely online and includes a very quick and fair peer-review system, which is all easy to use. Visit http://www.dovepress.com/ testimonials.php to read real quotes from published authors. 